little to one side. A left-handed man or a Japanese would turn off a shaving showing a left-handed coil.

In the narwhal, which usually has only the left tusk developed, this has a sinistral twist, and what is very strange is the fact that when, as a rarity, both tusks are grown, each has a sinistral spiral. In this specimen, with the undeveloped tusk embedded in the bone, it will be seen that the tusk, which is not erupted, has no evidence of the spiral marking, and therefore I conclude that the spiral is made after the eruption of the tusk, and may be due to the ploughing of the waves with the head on one side, a habit connected with the want of symmetry in the normal narwhal. The influence of moisture and want of friction is well seen in the horns of Falkland Island sheep, which are strangely intertwined.

With regard to the spiral horns in fossil state, the actual horn has of course long perished with the hide, but the horn cores, being of bone, have remained to show us that when spirals existed they took the same direction in ancestors and predecessors as in the species now living. In our Geological Museum among the horn cores of antelopes are fossil skulls which show clearly spirally-marked horn cores, heteronymous in direction. The horns observed were like the eland not an open spiral like the koodoo or Indian antelope. The best specimens were found in Greece, in upper miocene formation, by $M$. Gaudry. It is interesting to find the spirals taking this direction, and not as in the fossil whelk shell which went the opposite way from their modern representatives.

Although all living oxen have horns in both sexes, yet certain fossil species are known in which these are absent in at least the females, and it has been suggested that it is due to this circumstance that "polled" races of oxen are so readily produced, this being, in fact, a reversion to a condition in which both sexes of the ruminants were normally hornless.

In the ancient oxen when a spiral can be found in the horncores it takes the same direction as in existing oxen, that is, homonymously.

In watching the Alpine sheep, ${ }^{3}$ a domestic breed with curling horns, it is remarkable how the horns which are homonymous are arranged around the ear in such a manner that the ear lies in the long axis of the open spiral of the horn, and is caged in the interior. The ear is thus limited and hampered in its movements, and sometimes is dislocated out of the coil and rendered functionless as a movable funnel.

An extraordinary difference is seen in the wild sheep, especially to be noted in ovis nivicola. The horns in this creature are enormous, but the ear is remarkably short, though still situated exactly in the axis of the open spiral in such a fashion that the ear appears to be at the apex of a hollow cone formed by the great spiral horn. The form of the horn and the position of the ear enables the wild sheep to determine the direction of sounds; when there is a mist or fog acting like an Admiralty megaphone or like the topophone (a double ear-trumpet, the bells of which open oppusite ways) used on fog-bound British-American vessels to determine the direction of sound signals.

When a man wishes to hear accurately, and judge of the direction of sounds, he often curves his hand behind his ear and makes a sort of megaphone with his curved hand. This sheep, I contend, has his horn so fixed and coiled round his ear that it acts like the man's hand, but the horn being of enormous size and of suitable shape is still more useful as a megaphone or hearing horn.

In fine old Scottish rams the ears are often squeezed and hampered by the growth of the horns, and in scores of Alpine sheep I have observed the ears caged in the open spiral of the horn, limited in movement and sometimes displaced altogether, hampered and useless. It is probably an example like the drooped ears described by Darwin of variation of animals under domestication.

Our domesticated quadrupeds are all descended, as far as is known from species having erect ears; yet few kinds can be named of which a least on 3 race has not drooping ears. Cats in China, horses in parts of Russia, sheep in Italy and elsewhere, the guinea-plg formerly in Germany, goats and cattle in India, rabbits, pigs, and dogs in long-civilized countries have dependent ears.

With wild animals, which constantly use their ears like funnels to catch every passing sound, and especially to ascertain the direction whence it comes, there is not, as Mr. Blyth has remarked, any species with droopin ears except the elephant. Hence the incapacity to erect the ears is certainly in some manner the result of domestication, and this incapacit has been attributed by various authors to disuse, for animals protected by man are not eompelled habitually to use their ears.
In ovis nivicola, though the external ear is present, it is very little more use as a movable funnel than is the ear of a man, and it is notorious how difficult it is for man to judge of the direction of sound.

In animals protected by man, the interference with the function of the ear is of no consequence. It is a far different affair for the wild sheep dependent for his defence on his fine sense organs, and, at least in north Kamschatka, liable to be enveloped in mist and fog. If the creature had a large ear, and could turn it to all parts of the compass, it would turn its funnel to a rampart of horn which backs and partly surrounds the ear, in fact the external ear, would be of little value. In these sheep with horns, as described, the ear is small, and in ovis nivicola the smallest of all.

By taking the horn off the skull the listening ear, if properly placed, can distinguish the tick of a watch in one position best-namely, in the long axis of the coil-and thus test the value of the horn for determining the direction of sounds. The megaphone, it will be noted, differs from the ordinary ear trumpet, inasmuch as the smaller end surrounds the ear and may be pressed against the head, it has no earpiece to fit into the external auditory meatus, and is used either to shout or listen through.

Taking advantage of our Cambridge museums, I am enabled to illustrate my remarks with these selected specimens. I hope it will be forgiven me that I have diverted you from themedical and morbid track for a few moments. It has been well said that "observation is the most enduring of the pleasures of life," and it has been my endeavour to share with you " in glimpses which shall make us less forlorn," even if it be beyond our power to gain a sight of "Proteus rising from. the sea or hear old Triton blow his wreathed horn." 1 Lancet, January rst, r898. ${ }_{4}^{2}$ Nature. ${ }_{4}^{3}$ Nature, December 12th, 19or.

\section{A SIMPLE AND EFFECTUAL METHOD OF STERILIZING CATGUT.}

BY A. W. MAYO ROBSON, F.R.C.S.

Vice-President of the Royal College of Surgeons of England.

A GROWING sense of the superiority of readily absorbablematerial such as catgut for ligatures and buried sutures, if only one could be sure of its absolute asepticity, and the acknowledged uncertainty of the commercial preparations, led me to make some experiments on the effect of heating catgut. in substances other than water with a view of determining. whether after heating for some time to a temperature of $100^{\circ} \mathrm{C}$., it would still be sufficiently strong to be employed as. a suture or ligature. At first I used methylated spirit, which was heated in a cylinder made for me hy Messrs. Down. Brothers, and specially prepared to withstand the pressure under which spirit would be when subjected to the temperature of boiling water. The results obtained were satisfactory: the catgut, after being heated in alcohol for twenty minutes, being quite as strong as before heating. This substance was. given up only because it was considered inadvisable to run. the risk of an explosion if some fluid equally suitable in other respects could be obtained which had a boiling point higher than water. Three substances were selected: aniline, the boiling point of which is $184.5^{\circ} \mathrm{C}$; xylol (di-methyl-benzene) which boils at about $140^{\circ} \mathrm{C}$.; and glycerine, the boiling point. of which is above $100^{\circ} \mathrm{C}$., and which at ordinary atmospheric pressure decomposes before it reaches its boiling point. Trials. with each of these three substances left the catgut strong, but, on the whole, xylol has been found to give the best results, and indeed, when it is used, the result is better than with methylated spirit, the catgut shrinking, gaining in strength, and "biting" better when tied. For some time II have used catgut, usually the "o" size, prepared in this way, and I have had every reason to be satisfied with it.

At the outset I used the chromic catgut, but I found this persisted too long in the tissues, sometime appearing to be quite unabsorbable. I have, however, for the past year or. two employed either the ordinary unmedicated catgut, or, better still, the formalin catgut prepared by Messrs. Macfarlane of Edinburgh. At first I used to wind the catgut loosely 
on glass reels, but this is quite unnecessary, and I now simply undo the constricting centre of each skein and reapply it loosely, thus avoiding constriction of the skein in the centre, and enabling the heated fluid to reach every part of the catgut. The skeins are then introduced into a metal cylinder (made for me by Messrs. Down Brothers), the cap of which screws on, and after the cylinder has been filled with xylol, the cap is screwed up very firmly, as it is quite fatal to the preparation either to allow any water to enter the cylinder or to allow the xylol to evaporate. The cylinder is then put into the sterilizer and boiled for at least half an hour. After being thus sterilized, the catgut is stored in 5 per cent. carbolic acid solution in methylated spirit.

So far as I can say, it keeps indefinitely, so that any quantity can be prepared at one time. When operating, I use the ligatures out of $I$ in 20 carbolized spirit.

\section{MEMORANDA: \\ MEDICAL, SURGICAL, OBSTETRICAL, THERA- PEUTICAL, PATHOLOGICAL, ETc.}

\section{OLD.STANDING IRREDUCIBLE HERNIA, WITH RE- PEATED ATTACKS OF OBSTRUCTION : RESECTION OF THE IRREDUCIBLE MASS, CONTAINING SIX FEET OF INTESTINE : COMPLETE RECOVERY.}

W. J., aged 59, had suffered for ten years from a left inguinal hernia. For past three months it had apparently been only partially reducible, and he had suffered from attacks of subacute obstruction. On May I th, Igor, the hernia increased considerably in size and became completely irreducible. He was seized with abdominal pain and vomiting, and was sent to hospital on May I6th, 1901.

His condition at that time was described as follows: A well-nourished man, with a big heavy tumour in the left side of the scrotum about the size of a man's head, which was painful, tender, irreducible, and tympanitic. Colicky pain in the abdomen, nausea, and slight vomiting; urine was normal heart sounds faint and irregular, and he had some chronic bronchitis. As there were no signs of strangulation he was treated by copious enemata, elevation of the tumour, and strychnine given hypodermically-but as relief was not obtained operation was decided upon.

May i8th, I9nr.-Methylene was selected as the anaesthetic owing to the state of the heart and lungs. On opening the sac a large coil of apparently normal intestine was exposed, but all efforts to reduce it failed, even after free division o the neck of the sac and abdominal wall. The causes of irreducibility were (I) a large overgrowth of fat between the layer of the mesentery ; (2) adhesions between the coils of intestine.

There were four alternatives: (I) Free division of the abdominal wall and forcible reduction. As this would certainly have been followed by rapid recurrence, it was at once negatived. (2) To attempt removal of the fatty growth and then reduce the bowel. As the interference with the mesenteric vessels involved in this proceeding would have resulted in gangrene of the bowel, it was also discarded. There only remained (3) to resect the offending mass; (4) to close the wound, leaving the herniz in situ.

After a hurried consultation with my colleague, Mr. Kirk, resection was decided on. The entire contents of the sac were removed as rapidly as possible, and the ends of the bowel united by double row of continuous suture withou artificial support. The hernial sac was next removed and an attempt at a radical cure carried out. Shock was profound, Bout the patient rapidly rallied. The portion of intestine removed on subsequent measurement was found to be six feet in length. It certainly did not appear at the time of operation to be nearly so long, or probably I would not have removed it. Recovery was uninterrupted, with the exception of some local suppuration which necessitated the removal of the deep sutures about three weeks after operation. On the third day slight diarrhoea set in and continued some time.

At the end of the first week he began to suffer from continuous drowsiness, and this symptom persisted till his dis- charge to the Convalescent Home six weeks after operation. It then rapidly disappeared, and he is now quite well and attending his business, apparently suffering no inconvenience from the loss of the six feet of intestine.

The hernia up to the present has shown no sign of recurrence, and it is now sixteen months since operation. I have thought this case worthy of record on account of (I) the great length of intestine successfully removed in a patient in his 6oth year; (2) the curious drowsiness which followed the removal for a limited period; (3) the absence of any permanent ill-effect from the loss of so much of the digestive tract; (4) the rare condition which caused the irreducibility, that ie, overgrowth of fat between the layers of the mesentery. A. B. Mitchell, M.B., F.R.C.S.I.

Surgeon, Royal Victoria Hospital, Belfast.

\section{DOUBLE EMPYEMA OF TUNICA VAGINALIS IN} SCARLET FEVER.

ON March 24th a boy, aged 4, developed an atttack of scarlet fever, which ran a normal course for three weeks. There was no albumen, and the patient was allowed to get up at the end of this period. A week later he complained of pain in the lower abdomen, and vomited frequently; there was considerable constitutional disturbance - temperature $103.5^{\circ}$ within 24 hours. The scrotal integuments became red and infiltrated and both testicles very hard and swollen. The next day there was every appearance of suppuration, and a small incision on each side was therefore made through the inflamed tissues into the tunica vaginalis, when a quantity of thick yellow pus escaped. There was no discharge on incising the superficial structures, so that the condition was not a mere cellulitis of the scrotum. The testes felt enlarged and hard, but there was no evidence of suppuration in the organs themselves.

A drain was inserted into each wound. The inflammatory condition speedily subsided, and the wounds healed without any tendency to the formation of a hernia testis. There was no parotitis at any period of the illness.

Lowestoft.

KELOID IN VACCINATION SCARS.

ThE following two cases of keloid developing in the cicatrices after vaccination may be of interest and worth recording, especially as the condition occurred only in the scars after primary vaccination of two children, both females, at a time when I was vaccinating a great many, all the remainder, to the best of my recollection, being cases of revaccination.

A., a girl, aged 8 years, was primarily vaccinated by me last October in three places. All took well and followed the usual course; alfew weeks back the child was brought to me with keloid developed in each cicatrix. The slightest pressure causing great pain, they were removed.

B., a girl aged 14 years, was also vaccinated for the first time in January last in the same number of places and with exactly the same result as in the first patient, for keloid developed in each cicatrix. The lymph was the same as $I$ have used for years, and that with which I did all of the many revaccinations with most satisfactory results.

Worthing. HENRY WIGGINS, M.R.C.S., L.R.C.P.

PROFUSE HAEMORRHAGE TREATED BY ADRENALIN. I HAVE had under observation for some years a lady, single, aged $3 \mathrm{I}$, who suffers three or four times yearly from severe haemorrhage per rectum. Menstruation occurs once every third month and is scanty and painful. Prolapsus ani has been present for at least six years but is not very troublesome. Constipation is very marked, and a soap and water enema has to be employed almost nightly. There are no haemorrhoids. So profuse is this occasional haemorrhage that the patient is almost always confined to bed for a day or two, and for some weeks afterwards is so anaemic, though naturally a fullblooded woman, that her friends comment on her pallid appearance. The heart, lungs, and other organs are apparently normal, and the urine is free from albumen. I have for some time regarded this case as one of vicarions menstruation, but have had little success in arresting the haemorrhage till some days ayo when I resolved to try adrenalin as prepared by Burroughs, Wellcome and Co. 